\title{
Research on Stability of Coal Pillars in Wongawilli Mining Area of Ganhe Colliery
}

\author{
Liang Tian ${ }^{1, a}$, Minzu $\mathrm{Li}^{1}$, Shaopeng Jiao ${ }^{1}$, Dongsheng Yang ${ }^{2}$, Xianghui Kang ${ }^{2}$
}

1. School of Mechanics and Civil Engineering, China University of Mining and Technology (Beijing), Beijing 100083,China

\author{
2. The 4th construction Co.,Ltd of China Railway NO.5 Engineering Group, Shaoguan \\ 512031,China \\ a cumtbtianl@126.com
}

Keywords: bound coal; Wongawilli mining method; coal pillars; numerical simulation

\begin{abstract}
In order to find a suitable technology for recovery of bound coal in China's Shanxi province, the Wongawilli mining method is applied in Ganhe colliery. Recovery rate depends on reasonable deign of rooms and pillars. Geological conditions of pilot area is complex, such as great burial depth, poor integrality and latent underground water. In consideration of that, the study was carried out in 2013. Site sampling, SEM (scanning electron microscope), XRD (X-Ray Diffraction) and some other mechanical equipment were used to test physical and mechanical parameters of surrounding rocks. The RQD (rock quality designation) is lower than 30\%, so the integrality of rocks is quite poor, the compressive strength is of high discrete. Then theory of simply supported beam and theory of clamped beam were used to acquire the reasonable span of roof rock. Finally, numerical models were founded to analyse deformation, plastic zone and stress evolution by FLAC $^{3 \mathrm{D}}$. Three different size of coal pillar were compared. We come to a conclusion that the suitable width of little pillar is $1.5 \mathrm{~m}$ in this mining area, it can guarantee stability of stope, meanwhile recovery rate is the highest.
\end{abstract}

\section{Introduction}

The recovery of bound coal is an effective way to increase mining rate of coal mine, and continuous miner is a good choice. Geological conditions of Wongawilli mining area in Ganhe colliery is complex, such as great burial depth, poor integrality and latent underground water. The arrangement and support design of roadways are all based on the properties of surrounding rocks and geological conditions. A great many experts in China have done much work to develop the mining technology.

After three different spurts of new Wongawilli mining method, a typical mining technology was formed in China Shenhua Shendong Coal Group[1]. Maopu Zhou[2]studied the application of Wongawilli mining method in Ulan Mulun colliery, it showed that the optimal span of branch roadways was from $5 \mathrm{~m}$ to $6 \mathrm{~m}$, and $120 \mathrm{~m}$ the length. The reasonable width of little pillars was from $0.3 \mathrm{~m}$ to $1.5 \mathrm{~m}$. A new kind of technology, named 'one excavation double rooms', was successfully applied in Dahaize colliery by Chengjun Zhou[3-5].Wen Li, Dayong Li[6,7] studied the dimension of utility pillars and limiting area of suspension roof. The monitoring system for ground pressure of shallow coal seam covered with thin bedrock was founded.

In order to find a suitable technology for recovery of bound coal in NO.1 mining zone, the study is settled on Wongawilli area in Ganhe colliery, Huozhou city, Shanxi province, which is famous for coal production.

\section{Geological conditions}

Fig. 1 shows the location of Wongawilli mining area and arrangement of roadways. It locates at a delta-shaped region, where 2-1121 roadway, 2-1122 roadway and trackway met. Those roadways have already done before. Depth of the area is about $330 \mathrm{~m}$, and it lies on the footwall of normal fault, whose fault displacement is $15 \mathrm{~m}$ and $60^{\circ}$ dip angle. There are 884,000 tons of coking coal 
buried underground. The size of main roadways and branch roadways is $5.5 \times 4.0 \mathrm{~m}$. The dimension of rooms is $11.0 \times 3.3 \times 4.0 \mathrm{~m}$. The average thickness of NO.2 coalbed is about $3.95 \mathrm{~m}$, its dip angle is from $3^{\circ}$ to $6^{\circ}$. There is a parting, whose thickness is $0.4 \mathrm{~m}$. Uniaxial compressive strength of the coal is from 4.1 MPa to 6.4 MPa.

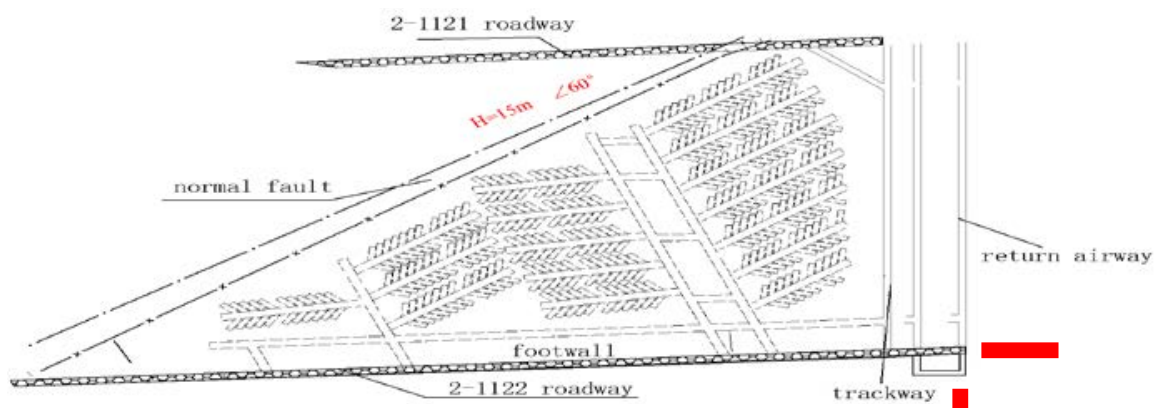

Fig.1 Sketch map of coal roadway in Wongawilli mir_ng area

\section{Test of mechanical parameters}

The ZDY-750 drilling machine was used for coring. 6 holes were finished at red sections in Fig.1. There are 22 pieces of roof rocks, and 18 out of them were longer than $10 \mathrm{~cm}$, the accumulated length was $242.5 \mathrm{~cm}$. Also there were 22 pieces of floor rocks, and 15 out of them were longer than $10 \mathrm{~cm}$, the accumulated length is $323.1 \mathrm{~cm}$. Base on the statistical result, the RQD values of roof and floor are all lower than $30 \%$, the result shows that the integrality of surrounding rocks is asymmetrical and poor. Fig.2 shows rock samples we processed and test machines. The test was carried out in the state key laboratory for geomechanics and deep underground engineering of China University of Mining and Technology (Beijing). Tab.1 shows the mechanical parameters of other roof rocks. The average compressive stress of the first roof rock is $55.5 \mathrm{MPa}$, and its tension is about $2.45 \mathrm{MPa}$.

Tab.1 Parameters of roof rocks

\begin{tabular}{ccccc}
\hline serial number & thickness[m] & rock name & elasticity modulus [GPa] & bulk density [kN/m $\left.{ }^{3}\right]$ \\
\hline 5 & 4.7 & siltstone & 47 & 27.3 \\
4 & 0.3 & coal streak & 8 & 13.2 \\
3 & 3.80 & mudstone & 13 & 25.7 \\
2 & 3.50 & post stone & 35 & 13.1 \\
1 & 6.34 & sandy mudstone & 26 & 26.5 \\
\hline & & & &
\end{tabular}

Fig.2 Rock samples and test of mechanical parameters

\section{Mechanical analysis of coal pillars}

The load, working on the first rock layer of roof, can be acquired by beam theory. The theory takes combined influence of overlying strata into consideration. According to mechanical parameters in Tab.1, when the value of $\left(q_{\mathrm{n}}\right)_{1}$ is lower than $\left(q_{\mathrm{n}-1}\right)_{1}$, we choose $\left(q_{\mathrm{n}-1}\right)_{1}$ as the effective load, as $E q 1$ shows. For $\left(q_{5}\right)_{1}<\left(q_{4}\right)_{1},\left(q_{4}\right)_{1}=246.63 \mathrm{kPa},\left(q_{4}\right)_{1}$ is chosen as even load $q$ finally.

$$
\left(q_{n}\right)_{1}=\frac{E_{1} h_{1}^{3}\left(\gamma_{1} h_{1}+\gamma_{2} h_{2}+\cdots+\gamma_{n} h_{n}\right)}{E_{1} h_{1}^{3}+E_{2} h_{2}^{3}+\cdots+E_{n} h_{n}^{3}}
$$

Theory of simply supported beam. Take per width of roof as a unit of simply support beam, the shear stress and normal stress of any point $o$ in beam is $E q 2$. For the result caused by shear stress is 
usually much greater than that of normal stress, calculation is based on normal stress. After all, the minimum value is taken in roadway design.

$$
\sigma_{x}=\frac{12 M_{x} y}{h^{3}}
$$

In this mechanical model, max moment occurs at the middle section of beam, at this section, value of bending moment is $M_{\max }=q L^{2} / 8$, the letter $q$ means even load working on rock beam. maximum tensile stress lie on lower surface and upper surface the max compressive stress. Beam failure is justified by max tensile stress, when $\sigma_{\max }=R_{T}$, those two equations above are substituted into $E q$ 2, the limited span of simply supported beam is $E q 3$.

$$
L_{l t}=2 h \sqrt{\frac{R_{T}}{3 q}}=2 \times 6.35 \times \sqrt{\frac{2450}{3 \times 246.63}}=23.11 \mathrm{~m}
$$

Theory of clamped beam. Based on this beam theory, deflection is different from that of simply supported beam. At the middle section, the bending moment of clamped beam is $M$ ${ }_{\max }=q L^{2} / 12$. The result of $E q 4$ is greater than that of simply supported beam, so value of $E q 3$ is chosen to be a maximum span.

$$
L_{l t}=h \sqrt{\frac{2 R_{T}}{q}}=6.35 \times \sqrt{\frac{2 \times 2450}{246.63}}=28.30 \mathrm{~m}
$$

Safety factor. Usually a safety factor $F$ is used to avoid failure caused by unexpected conditions and make sure stability of stope further, its common value is $2 \sim 4$, as shown in $E q 5$, so roof span $L_{\text {lt }}$ is $E q 6$ if safety factor $F$ is 2 . According to test results of sandy mudstone of roof, the rock is hard and brittle, but its integrality is quite poor. For high recovery rate and roof control by caving, the maximum span of roof is $16.34 \mathrm{~m}$.

$$
\begin{gathered}
R_{T}=\sigma / F \\
L_{l t}=2 h \sqrt{\frac{R_{T}}{3 q F}}=2 \times 6.35 \times \sqrt{\frac{2450}{3 \times 246.63 \times 2}}=16.34 \mathrm{~m}
\end{gathered}
$$

Strength of little pillars. The maximum uniaxial compressive strength of the coal is $6.4 \mathrm{MPa}$, so according to Obert-Dwvall/Wang formula, strength of little pillar $R$ is Eq 7.

$$
R=R_{C}\left(0.778+0.222 \frac{B}{h}\right)=6.4 \times\left(0.778+0.222 \frac{3.3}{4}\right)=6.15 M P a
$$

Method of auxiliary area. Fig. 3 shows mechanical model of pillar load. When mining area is large enough, dimension of pillars is regular, and rock layer is flatly inclined, overlying rock of rooms transfer to adjacent pillars. Right now, all pillars bear most mining pressure together, the load equals to all upper rocks including one and a half pillar width around little pillar.

Taking the worst mining conditions into consideration, as Fig.3 (b) shows, according to ultimate strength theory, the pillar strength $R$ should be greater than the even load $Q$ working on pillar width $w+B$. For the first pilot, we choose safety factor $F=4$ to calculate, Based on $E q$ 8, pillar width $w$ is no less than $0.65 \mathrm{~m}$. Considering the exfoliation natural and mechanical execution, $1.5 \mathrm{~m}$ is reasonable.

$$
6.15 \times 10^{6} \geq \frac{246.63 \times 10^{3}(w+3.3)}{w} \times 4
$$

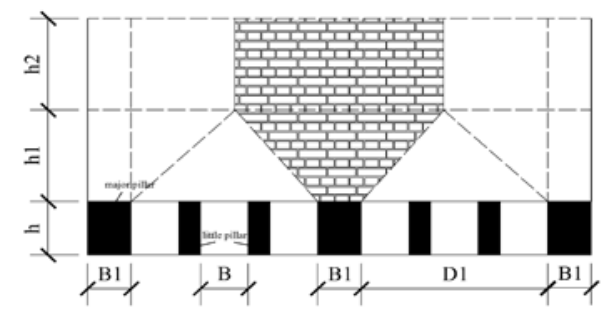

(a) load of major pillar

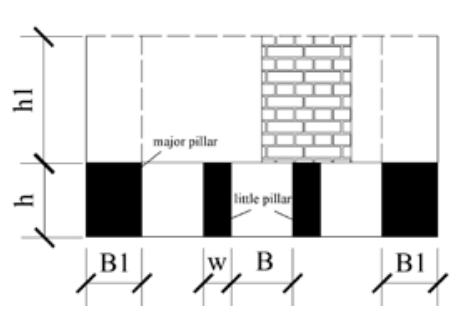

(b) load of little pillar

Fig.3 Sketch map of load working on pillars 


\section{Numerical simulation}

According to original rock formation, the numerical model was founded by FLAC3D, as shown in the Fig.4. Its dimension was $70 \times 2 \times 45 \mathrm{~m}$. There were totally 240,000 units and 362,193 joints. All surfaces were fixed except the upper surface. The even load $q$ worked on upper surface, the value of it was $7.5 \mathrm{MPa}$, which was acquired by heim's hypothesis. The pink part meaned NO.2 coal bed. The rooms were excavated in sequence. We planned to excavate 8 rooms, so 6 little pillars and 1 major pillar were left to support overlying rocks. Width of little pillar was changed from $1.0 \mathrm{~m}$ to $2.0 \mathrm{~m}$, and room number was the same. Fig.5 shows 11 monitoring points in the numerical model. The monitoring points of roof deformation is from 1 to 4 . Two monitoring points, using to record floor deformation, is NO.5 and NO.6, then NO.7 point is for boundary, the monitoring points of little pillars is from 8 to 10, NO.11 point is used to monitor deformation of major pillar.

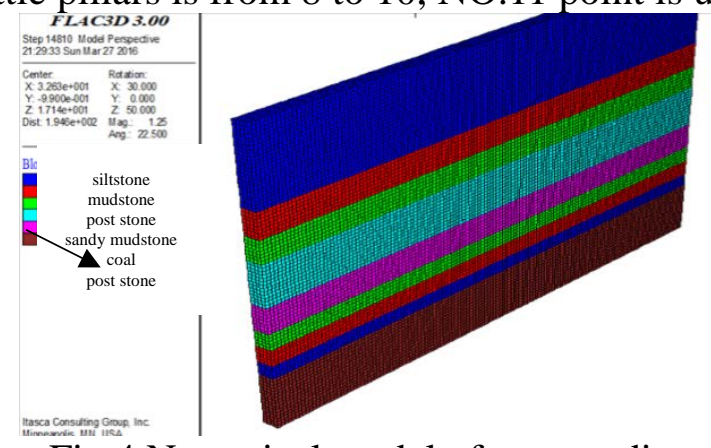

Fig.4 Numerical model of surrounding rocks

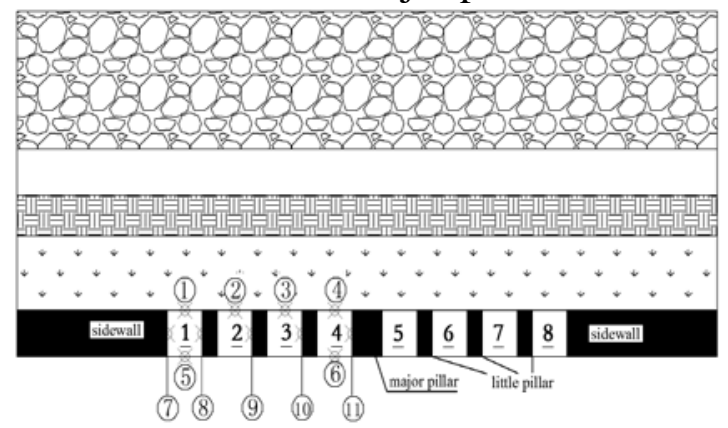

Fig.5 Positions of monitoring points

Vertical displacement. Fig.6 shows vertical displacement of three different pillar width. As shown in the Fig.6 (a), when width of little pillar is $1.0 \mathrm{~m}$, deformation diagram is very different from the other two. The maximum deformation occurs at the middle of rooms. Roof deformation is obviously great than floor deformation, the maximum deformation of roof is $61.2 \mathrm{~cm}$. According to large deformation, we can sentence that all pillars are out of work. For failure of little pillars, a large arched structure forms in roof rocks. When pillar width increases to $1.5 \mathrm{~m}$, the maximum deformation of roof is $14.1 \mathrm{~cm}$, deformation of surrounding rock declines drastically, so pillars have great effect on stability of stope if width of little pillar is no less than $1.5 \mathrm{~m}$. We can see distribution of vertical deformation in the Fig.6 (c), balanced arch appears in roof of each mining room. The maximum deformation of roof is $2.9 \mathrm{~cm}$, and $0.8 \mathrm{~cm}$ deformation of floor. Although stope is more stable as increase of pillar width, recovery rate is lower than that of $1.5 \mathrm{~m}$ wide. In consideration of roof control and recovery rate, $1.5 \mathrm{~m}$ is optimal value of pillar width.

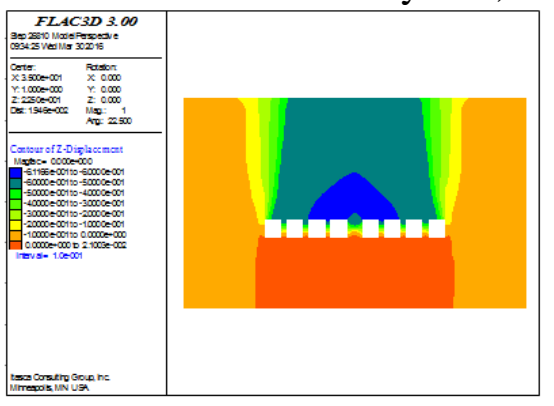

(a)1.0 m

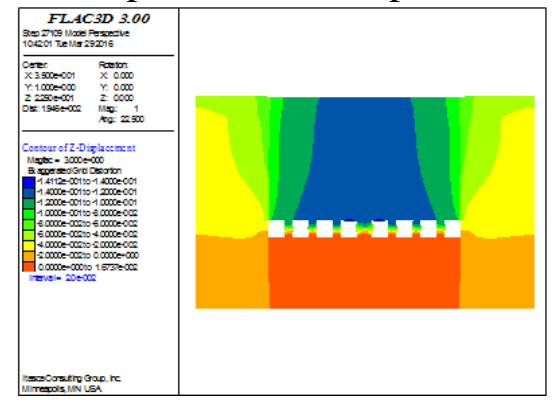

(b) $1.5 \mathrm{~m}$

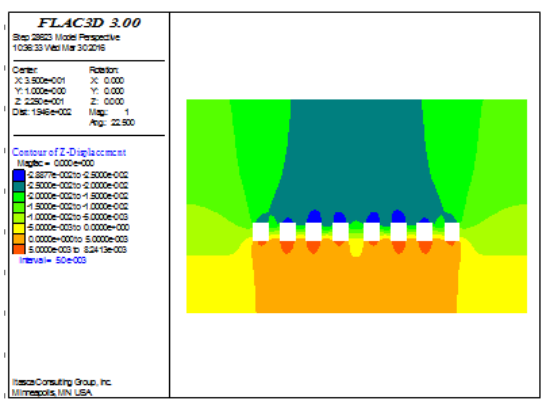

(c) $2.0 \mathrm{~m}$

Fig.6 Vertical displacement diagram of different pillars width

Horizontal displacement. Horizontal deformation is also quite important to pillar stability. It commonly occurs at two sidewalls and pillars. Based on results of monitoring points, from 7 to 11 , deformation of major pillar is maximum. When width of little pillars is $1.0 \mathrm{~m}$, the maximum deformation is $37.3 \mathrm{~cm}$, and $15 \mathrm{~cm}$ that of major pillar. As it goes to $1.5 \mathrm{~m}$, the maximum deformation decreases to $8 \mathrm{~cm}$ drastically, and $5 \mathrm{~cm}$ that of major pillar. It's of great distinction since coal pillars have supporting effect. The maximum deformation of surrounding rock is $0.9 \mathrm{~cm}$ when pillar width is $2.0 \mathrm{~m}$. Recovery rate will be uneconomical, and it will not good for roof control if the mining pressure can't release, which could be solved by caving usually.

Rock stress. Ground pressure will redistribute after excavation of rooms, original rock stress of 
overlying rocks concentrates on pillars. The main supporting effect is bound walls and major pillar if little pillars are not wide enough. Fig.7 shows vertical stress of different pillars width. Concentration zone of mining stress occurs at bound walls first, tensile stress appears at surface of roof and floor. The value of roof tensile stress is greater than that of floor, also the pressure of major pillar is greater than that of little pillars.

As shown in the Fig.7 (a), the maximum stress occurs at bound coal, which locates at two wings of mining rooms. Its maximum value is $19.6 \mathrm{MPa}, 10.3 \mathrm{MPa}$ little pillars, and $12 \mathrm{MPa}$ major pillar. The mining pressure is greater than compressive strength of pillars, whose value is $E q$ 9, all little pillars are failed. When pillar width is $1.5 \mathrm{~m}$, its maximum value is $18.6 \mathrm{MPa}, 4.3 \mathrm{MPa}$ little pillars, and 5.8 MPa major pillar. The results is lower than compressive strength of pillars, it can satisfy stability of stope. Arched structures form in roof of each room as pillar width becomes $2.0 \mathrm{~m}$, maximum of bound pressure is 18.3 MPa, 3.2 MPa little pillars, and 4.4 MPa major pillar. As the increase of pillar width, the mining load working on pillars decreases obviously, but recovery rate will reduce, so it's not economical.

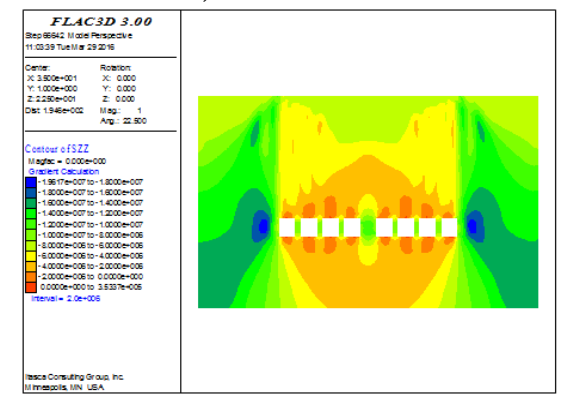

(a)1.0 m

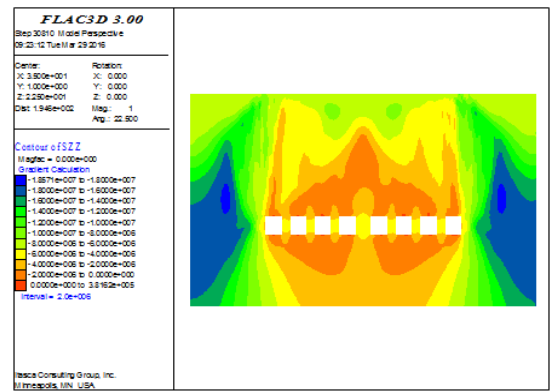

(b) $1.5 \mathrm{~m}$

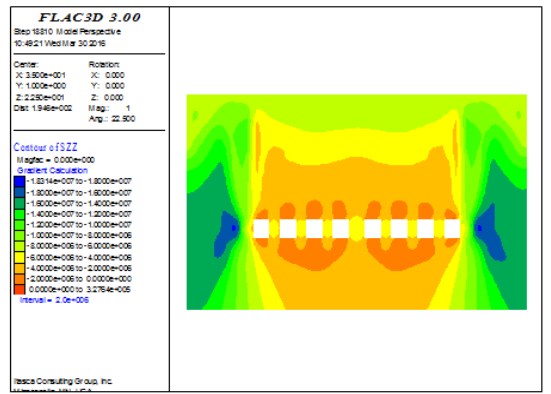

(c) $2.0 \mathrm{~m}$

Fig.7 Vertical stress diagram of different pillars width

Distribution of plastic zone. Fig.8 shows distribution of different pillar width. Roof and floor of stope mainly appear tensile stress, and shear stress pillars. From middle section of major pillar to bound walls, range and value of roof tensile stress becomes smaller and smaller. As shown in the Fig.8 (a), when width of little pillars is $1.0 \mathrm{~m}$, the value and range of plastic zone is widespread, it's distinctly wider than the other two figs. Roof rock is mainly tension-p. Tension-p means the roof, caused by tensile stress, has already failed. Plastic zone reach to $12 \mathrm{~m}$ above bound walls, $10 \mathrm{~m}$ roof of major pillar, and $5 \mathrm{~m}$ that of rooms, shear stress and tensile stress appear in little pillars, shear stress major pillar. When width of little pillars is $1.5 \mathrm{~m}$, range of plastic zone decreases obviously both in roof and floor, pillars have a supporting effect on overlying rocks. When width of little pillars is $2.0 \mathrm{~m}$, range of plastic zone in roof is two layers of units, and one lay units in floor. As pillar width increases, range of plastic zone decreases, coal pillars have great effect on ground stress distribution, which results in rock failure.

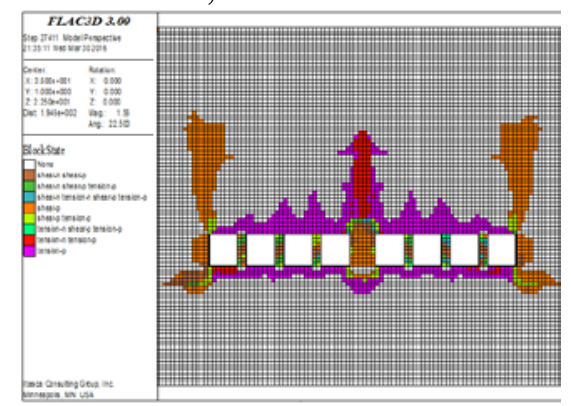

(a) $1.0 \mathrm{~m}$

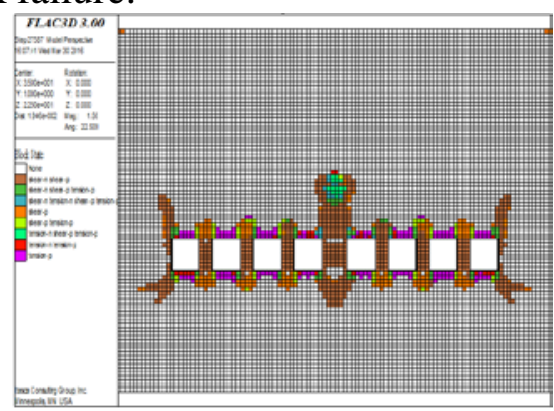

(b) $1.5 \mathrm{~m}$

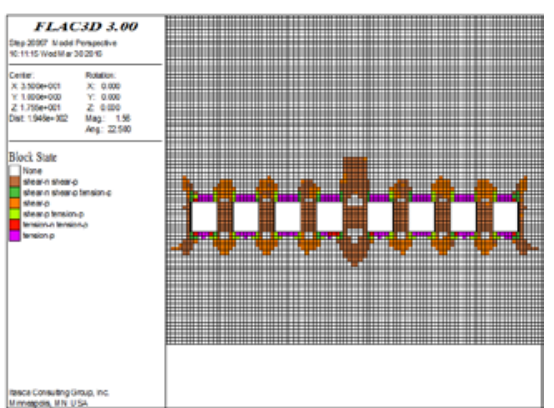

(c) $2.0 \mathrm{~m}$

Fig.8 Distribution of plastic zone of different pillars width

\section{Conclusions}

(1) The RQD values of both roof and floor are lower than $30 \%$, the integrality of surrounding rocks is asymmetrical and poor.

(2) Width of pillars has great effect on stability of Wongawilli mining area. As increase of pillar 
width, it could decrease deformation and mining pressure of pillars and surrounding rock,

(3)The suitable width of little pillars is $1.5 \mathrm{~m}$, and $3.0 \mathrm{~m}$ width of major pillar.

(4) When width of little pillars is lower than $1.0 \mathrm{~m}$, they would fail and have no support effect in this coal bed.

\section{Acknowledgements}

This work was financially supported by Ganhe Colliery, Houzhou Coal Electricity Group Co.,Ltd and State Key Laboratory for Geomechanics and Deep Underground Engineering of China University of Mining and Technology (Beijing).

\section{References}

[1] Zhifa Lu, Jianming Sun, Jin Pan, et al: Coal Science and Technology. Vol.30 (2002),p.11-17. (In Chinese)

[2] Maopu Zhou: China University of Mining and Technology. Xuzhou (2014). (In Chinese)

[3] Chengjun Zhou, Huajun Wang: Coal Engineering. Vol.8 (2007),p.5 8.(In Chinese)

[4] Huajun Wang: Coal Engineering. Vol.6 (2013),p.69 72.(In Chinese)

[5] Huajun Wang: Coal Engineering. Vol.41 (2013),p.9 13.(In Chinese)

[6] Wen Li, Zhi Hu: Coal Engineering. Vol.2 (2013),p.62 65.(In Chinese)

[7] Dayong Li: Shandong University of Science and Technology, Qingdao (2008). (In Chinese) 